\title{
Delayed improvement of autonomic nervous abnormality after the Maze procedure: time and frequency domain analysis of heart rate variability using 24 hour Holter monitoring
}

Kengo Fukushima, Tetsuro Emori, Wataru Shimizu, Takashi Kurita, Naohiko Aihara, Yoshio Kosakai, Fumitaka Isobe, Katsuro Shimomura, Yasunaru Kawashima, Tohru Ohe

\begin{abstract}
Objective-To analyse heart rate variability in patients with atrial fibrillation after the Maze procedure, to investigate whether the procedure damages the cardiac autonomic fibres supplying the sinus node.

Design and patients-Time and frequency domain analyses of $R R$ variability were performed using 24 hour Holter monitoring one month after surgery in 12 patients with atrial fibrillation who underwent the Maze procedure (Maze group) and in seven patients who underwent cardiac surgery without the Maze procedure (control group). Mean RR intervals (mRR) and the standard deviation of successive RR intervals (SDRR) were determined by time domain analysis, and high frequency (HF), low frequency (LF), and total power (TP) spectral components of RR variability were calculated by frequency domain analysis. Holter monitoring was also performed at six and 12 months after cardiac surgery in the Maze group.
\end{abstract}

Results-Circadian variation (mean (SD)) in $\mathbf{m R R}$ (daytime to night time difference: 119 (60) $v 302$ (143) ms), SDRR (daytime: 8.4 (3.3) $v 37.0(12.0) \mathrm{ms})$, TP (daytime: 46.7 (16.0) $v 171.8$ (30.4) ms), HF (daytime: $\left.19.6(9.9) \quad v \quad 36.7(7.1) \mathrm{ms}^{2}\right)$, and LF/HF (daytime: $0.31(0.07) v 1.18(0.46)$ ) was decreased in the Maze group at one month compared with the control group ( $p<0.01)$, but showed improvement at six and 12 months $(p<0.05)$.

Conclusions-Surgery combined with the Maze procedure markedly suppressed the circadian variation of heart rate over a 24 hour period within one month after surgery, mainly because of damage to the innervation of the sinus node. However, at six and 12 months there was restoration of circadian variation, probably as the result of reinnervation of the sinus node.

(Heart 1997;78:499-504)

Keywords: autonomic nervous system; heart rate variability; Maze procedure

Dr Fukushima, Department of Cardiovascular Medicine, Okayama University,

Shikata-cho 2-5-1, Okayama City, Okayama 700, Japan.

Accepted for publication 18 July 1997
Cox and his colleagues have reported that the Maze procedure stops atrial fibrillation and results in the maintenance of sinus rhythm, ${ }^{1-4}$ leading to haemodynamic benefits and restored atrioventricular mechanical synchrony. Kosakai et al subsequently modified the procedure to treat patients with mitral valve disease (Kosakai's modified Maze procedure). ${ }^{5}$ However, it has often been observed that the sinus node response to exercise is attenuated early after the procedure. ${ }^{6}$ We hypothesised that the Maze procedure may damage the autonomic fibres supplying the sinus node. We analysed heart rate variability using both time and frequency domain analyses in patients with atrial fibrillation after the Maze procedure.

\section{Methods}

PATIENTS

We studied 12 patients who underwent cardiac surgery with the Maze procedure (Maze group, mean (SD) age 57 (9) years; table 1). We excluded patients with a history of myocardial infarction, chronic obstructive pulmonary disease, renal failure, diabetes mellitus, severe systemic diseases, severe congestive heart failure (New York Heart Association grade III-IV), or frequent extrasystoles (more than 10 ectopic atrial or ventricular contractions per hour). Atrial fibrillation was permanent in 10 patients and paroxysmal in two. All patients were in sinus rhythm after the Maze procedure. None of the patients received $\beta$ blockers, calcium antagonists, or angiotensin converting enzyme inhibitors after the Maze procedure, but six were on digitalis and two on disopyramide. As a control group we also studied seven patients who underwent cardiac surgery without the Maze procedure (mean age 53 (8) years; table 1 ), who were in sinus rhythm before and after surgery. In this group, four patients received digitalis and two received disopyramide after surgery.

\section{DOPPLER ECHOCARDIOGRAPHY}

Cross sectional and Doppler echocardiographic examinations using a commercially available, real time, cross sectional, Doppler colour flow imaging system were performed before and within one month after surgery in all patients. Routine cross sectional and Doppler data were obtained with a $2.5 \mathrm{MHz}$ and a $3.0 \mathrm{MHz}$ transducer and recorded on a hard copy printout at paper speeds of $50 \mathrm{~mm} / \mathrm{s}$. The transmitral flow profile was obtained from apical window. 
Table 1 Patient characteristics

\begin{tabular}{|c|c|c|c|c|c|c|c|c|}
\hline \multirow[b]{2}{*}{ Case number } & \multirow[b]{2}{*}{ Age } & \multirow[b]{2}{*}{ Sex } & \multirow[b]{2}{*}{ Disease } & \multirow[b]{2}{*}{ Operation } & \multicolumn{2}{|c|}{$L A D(\mathrm{~mm})$} & \multicolumn{2}{|l|}{ Atrial fibrillation } \\
\hline & & & & & Before & After & Duration (years) & Type \\
\hline \multicolumn{9}{|l|}{ Maze group } \\
\hline 1 & 39 & $M$ & Lone AF & & 32 & 31 & 10.7 & Paroxysmal \\
\hline 2 & 51 & $M$ & VSD & Closure & 32 & 31 & 3.3 & Paroxysmal \\
\hline 3 & 53 & $\mathrm{~F}$ & ASR, MSR & DVR & 58 & 35 & 10 & Sustained \\
\hline 4 & 46 & $\mathrm{~F}$ & $\operatorname{PVF}(\mathrm{M})$ & MVR & 58 & 40 & 9 & Sustained \\
\hline 5 & 52 & M & ASR, MR & DVR & 61 & 50 & 0.1 & Sustained \\
\hline 6 & 70 & $M$ & MR & MV plasty & 80 & 37 & 2.5 & Sustained \\
\hline 7 & 59 & $M$ & MSR & MVR & 62 & 52 & 1.4 & Sustained \\
\hline 8 & 64 & $M$ & MR & MVR & 56 & 39 & 11.5 & Sustained \\
\hline 9 & 59 & $M$ & MR & MV plasty & 52 & 51 & 4.9 & Sustained \\
\hline 10 & 68 & $\mathrm{~F}$ & MSR & MVR & 72 & 52 & 3.3 & Sustained \\
\hline 11 & 67 & $\mathrm{M}$ & MSR, AR & MVR & 52 & 42 & 5 & Sustained \\
\hline 12 & 52 & $M$ & MSR, AR & DVR & 45 & 44 & 21 & Sustained \\
\hline Mean & $57(9)$ & & & & $55(14)$ & $42(8)^{\star}$ & $6.9(5.9)$ & \\
\hline \multicolumn{9}{|l|}{ Control group } \\
\hline 1 & 54 & $\mathrm{~F}$ & ASD & Closure & 34 & 27 & Sinus & \\
\hline 2 & 59 & $\mathrm{~F}$ & ASD & Closure & 37 & 32 & Sinus & \\
\hline 3 & 45 & M & VSD & Closure & 43 & 39 & Sinus & \\
\hline 4 & 63 & $\mathrm{~F}$ & ASD & Closure & 30 & 30 & Sinus & \\
\hline 5 & 40 & M & ASD & Closure & 34 & 29 & Sinus & \\
\hline 6 & 49 & $\mathrm{~F}$ & ASD & Closure & 36 & 31 & Sinus & \\
\hline 7 & 59 & $\mathrm{~F}$ & MR & MVR & 62 & 39 & Sinus & \\
\hline Mean & $53(8)$ & & & & $39(11)$ & $32(5) \dagger$ & & \\
\hline
\end{tabular}

All data are expressed as mean (SD).

${ }^{\star} \mathrm{p}<0.01 v$ before surgery, $\mathrm{tp}<0.05 v$ after surgery in the Maze group.

$\mathrm{AF}$, atrial fibrillation; AR, aortic valve regurgitation; ASD, atrial septal defect; ASR, aortic valve stenosis and regurgitation; DVR, double valve replacement; MR, mitral valve regurgitation; MSR, mitral valve stenosis and regurgitation; MVR, mitral valve replacement; PVF (M), prosthetic valve failure (M position); and VSD, ventricular septal defect.

All examinations were performed in the supine position.

\section{THE MAZE PROCEDURE}

Beginning in April 1992, the Maze procedure was routinely combined with cardiac surgery to treat patients with organic heart disease and atrial fibrillation at the National Cardiovascular Centre. The operative procedure used in the present study was fundamentally the same as that initially described by Cox et $a l .{ }^{4}$ However, several modifications to the procedure $^{5}$ were used in the patients in the present study. In brief, a longitudinal incision was made in the atrial free wall from the right atrial appendage instead of the superior vena cava down to the inferior vena cava. Cryosurgery was used to avoid interrupting the sinus node arteries instead of incisions that transverse the sinus node arteries. ${ }^{7}$ Second, division of the superior vena cava was performed to improve the exposure of the mitral valve in patients who required surgical treatment to the mitral valve. This modification was also performed by Cox in his first modification of the Maze procedure. ${ }^{8}$

\section{HOUR HOLTER MONITORING AND HEART RATE} VARIABILITY

All patients underwent two channel 24 hour Holter monitoring within one month after surgery. Holter tapes were analysed using the DMC 4100 Holter System (Nihon Kohden, Tokyo, Japan), and the electrocardiographic data were digitised at $128 \mathrm{~Hz}$. QRS complexes detected over a 24 hour period were categorised as normal sinus beats, ectopic beats, artefacts, or unclassified. The accuracy of QRS detection and classification was reviewed by two physicians. Unclassified responses and artefacts were edited manually. RR interval data were transferred to a personal computer
(NEC PC 9800) after editing and analysis. Only normal to normal RR intervals were used for the measurement of RR intervals; defective data caused by ectopic beats and artefacts were interpolated using the cubic spline function.

The 24 hour digitally sampled ECG data were separated into segments of five minutes (288 segments in all). We selected two periods of 24 consecutive segments (two hours of data) from the 288 segments. One period was from the daytime (1000 to 1800) and included the shortest RR intervals (daytime data); the other period was from the night time (2200 to 0600) and included the longest RR intervals (night time data).

By time domain analysis, the means of the daytime and night time RR intervals (daytime $\mathrm{mRR}$, night time $\mathrm{mRR}$ ) were calculated for comparisons between the Maze and control groups. The means of the standard deviation of the five minute segments of successive normal $R R$ intervals for the daytime (daytime SDRR) and night time data (night time SDRR) were also calculated. We then determined the difference in $\mathrm{mRR}$ between daytime and night time $(\Delta \mathrm{mRR})$ as an index of the circadian variation in heart rate.

Spectral plots were computed in segments of five minutes using a 1024 point fast Fourier transform algorithm with a frequency resolution of $1 / 300(0.0033) \mathrm{Hz}$. A Hanning window function was used to minimise spectral leakage between segments without diminishing the frequency resolution. We determined the average low frequency (LF; 0.04 to $0.15 \mathrm{~Hz}$ ), high frequency $(\mathrm{HF} ; 0.15$ to $0.40 \mathrm{~Hz}$ ), and total power spectral components of heart rate variability (TP; 0.0033 to $1.0 \mathrm{~Hz}$ ) in the daytime and night time data. Patients were asked to keep a diary during the recording period. 


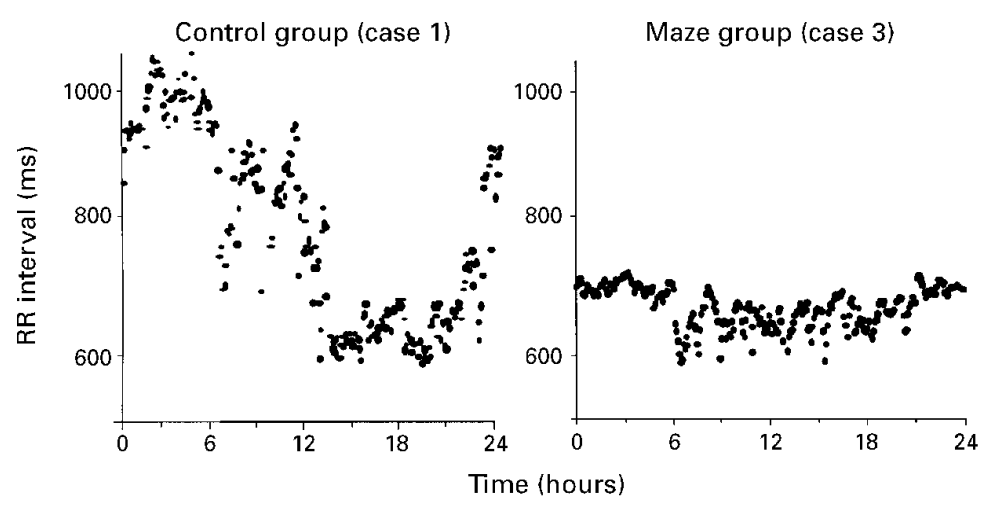

Figure 1 Mean RR intervals of five minute segments over 24 hours, within one month of surgery in a representative patient from the control group (left) and the Maze group (right).
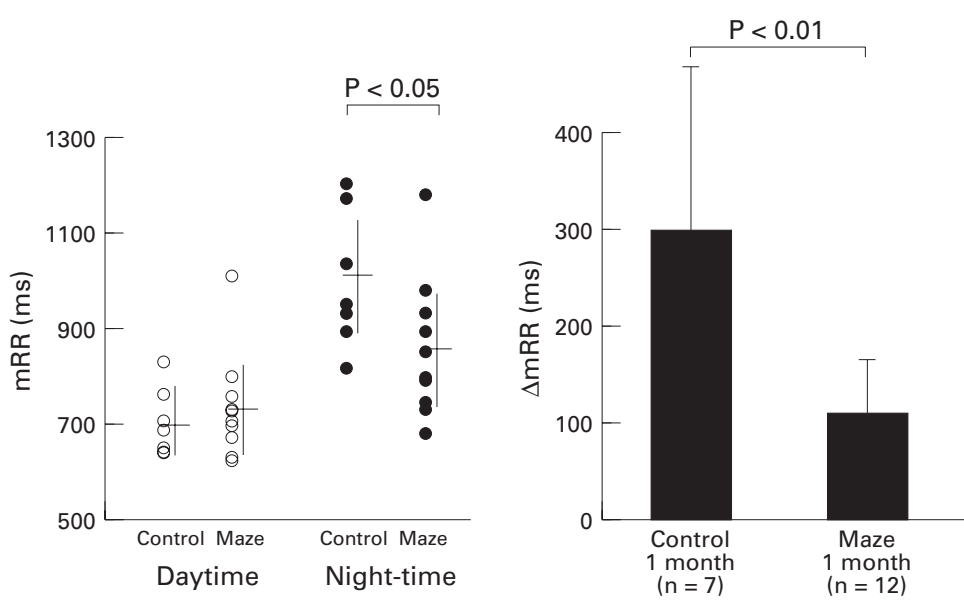

Figure 2 Left: $m R R$ within one month after surgery. Empty circles: daytime $m R R$; filled circles: night time $m R R$. Right: $\triangle m R R$ within one month after surgery. $\Delta m R R$, difference in $m R R$ values between daytime and night time; $m R R$, mean $R R$ intervals in two hours of data.
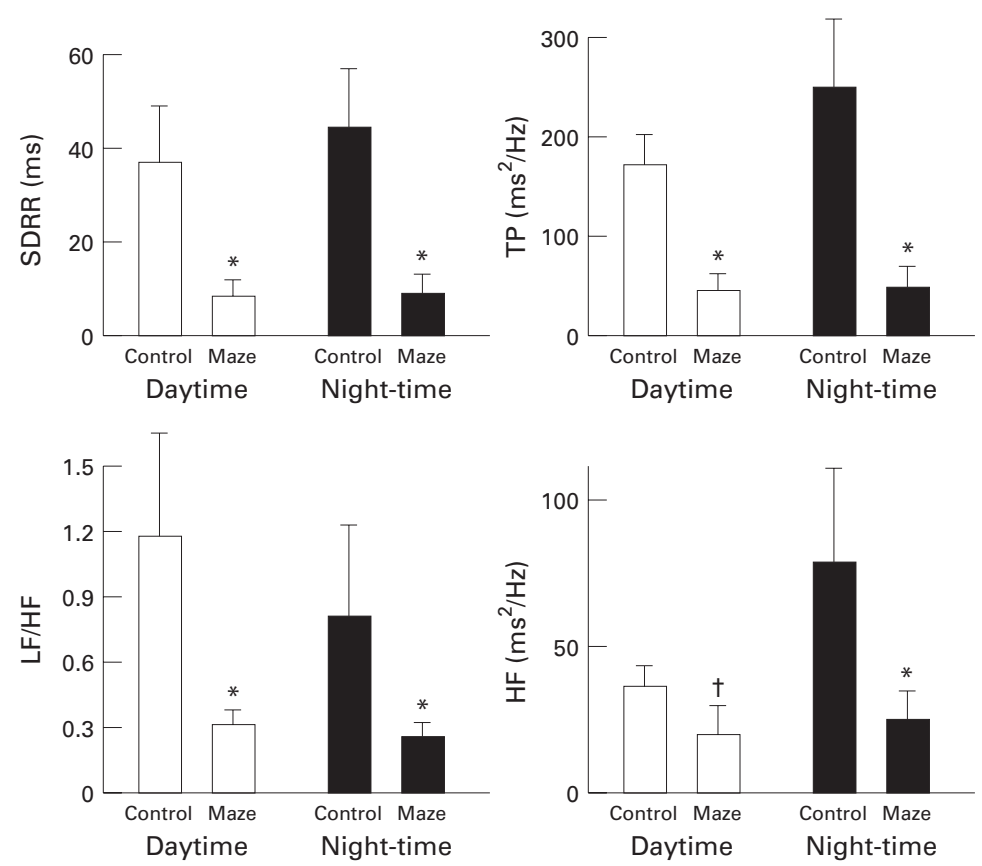

Figure 3 Time and frequency domain analyses of heart rate variability. $H F$, high frequency component of heart rate variability in two hours of data; LF, low frequency component of heart rate variability in two hours of data; SDRR, mean of standard deviation of five minutes of successive normal RR intervals in two hours of data; TP, total spectral components of heart rate variability in two hours of data.
SERIAL CHANGES IN HEART RATE VARIABILITY AFTER THE MAZE PROCEDURE

Holter monitoring was also performed at six and 12 months after surgery. We were unable to evaluate two patients for follow up heart rate variability (cases 9 and 10) because of frequent ectopic beats.

STATISTICAL ANALYSIS

Data are expressed as mean (SD). Statistical analysis was performed with commercially available software (Statview 4.0) using the Mann-Whitney $U$ test to analyse the differences between the Maze and control groups. Differences after surgery in the Maze group were analysed using repeated measures ANOvA with Bonferroni's correction. A p value of $<0.05$ was accepted as significant.

\section{Results}

ATRIAL DIMENSION AND FUNCTION AFTER THE MAZE PROCEDURE

The postoperative atrial dimension was larger in the Maze group than in the control group $(\mathrm{p}<0.05)$ (table 1), but the left atrial dimension decreased after surgery in the Maze group $(\mathrm{p}<0.01)$. The transmitral flow profile showed the presence of atrial waves in all patients in the Maze group.

\section{RR VARIABILITY}

Figure 1 shows a representative case of mean RR intervals of five minute segments over 24 hours in a Maze patient (case 3) and a control patient (case 1) within one month of surgery. The circadian variation of mean $R R$ intervals was significantly decreased after surgery in the Maze patient compared with the control patient.

The daytime $m R R$ values (two hours of data) were slightly longer in the Maze group (725 (104) $\mathrm{ms}$ ) than in the control group (697 (72) ms), but the difference was not significant (fig 2 left, empty circles). The night time $\mathrm{mRR}$ values (two hours of data) were significantly shorter in the Maze group (845 (137) $\mathrm{ms}$ ) than in the control group (999 (144) ms) ( $<<0.05$, fig 2 left, filled circles). Thus $\Delta \mathrm{mRR}$ (difference in $\mathrm{mRR}$ values between daytime and night time) was significantly smaller in the Maze group (119 (60), range 14.6 to $139.6 \mathrm{~ms}$ ) than in the control group (302 (143), range 175.2 to $557.4 \mathrm{~ms})$ ( $\mathrm{p}<0.01$, fig 2 right).

In time domain analysis of heart rate variability, the daytime SDRR was less in the Maze group (8.4 (3.3), range 4.5 to $13.7 \mathrm{~ms}$ ) than in the control group (37.0 (12.0), range 19.3 to $54.1 \mathrm{~ms}$ ) ( $\mathrm{p}<0.01$, fig 3, left upper). Night time SDRR was also significantly less in the Maze group (9.2 (3.8), range 5.3 to $17.4 \mathrm{~ms})$ than in the control group (44.1 (12.4), range 28.7 to $65.1 \mathrm{~ms})(\mathrm{p}<0.01$, fig 3, left upper).

In frequency domain analysis, the daytime TP was decreased in the Maze group (46.7 (16.0), range 34.0 to $62.8 \mathrm{~ms}^{2} / \mathrm{Hz}$ ) compared with the control group (171.8 (30.4), range 110.8 to $204.5 \mathrm{~ms}^{2} / \mathrm{Hz}$ ) ( $\mathrm{p}<0.01$, fig 3 , right upper). Night time TP was also decreased 
Table 2 Follow up data on heart rate variability in the Maze group

\begin{tabular}{|c|c|c|c|c|c|c|}
\hline & \multicolumn{3}{|l|}{ Daytime } & \multicolumn{3}{|l|}{ Night time } \\
\hline & 1 month & 6 months & 12 months & 1 month & 6 months & 12 months \\
\hline $\operatorname{SDRR}(\mathrm{ms})$ & $\begin{array}{l}8.4(3.3) \\
(4.5 \text { to } 3.7)\end{array}$ & $\begin{array}{l}16.6(5.2)^{\star} \\
(9.9 \text { to } 27.1)\end{array}$ & $\begin{array}{l}32.1(13.1)^{\star} \ddagger \\
(8.7 \text { to } 51.0)\end{array}$ & $\begin{array}{l}9.2(3.8) \\
(5.3 \text { to } 17.4)\end{array}$ & $\begin{array}{l}22.0(13.6)^{\star} \\
(7.3 \text { to } 52.0)\end{array}$ & $\begin{array}{l}30.0(18.3)^{\star} \\
(7.5 \text { to } 58.8)\end{array}$ \\
\hline $\mathrm{TP}\left(\mathrm{ms}^{2} / \mathrm{Hz}\right)$ & $\begin{array}{l}46.7(16.0) \\
(34.0 \text { to } 62.8)\end{array}$ & $\begin{array}{l}95.7(44.6)^{\star} \\
(52.2 \text { to } 200.8)\end{array}$ & $\begin{array}{l}144.6(68.8)^{\star} \\
(48.4 \text { to } 255.0)\end{array}$ & $\begin{array}{l}51.8(19.4) \\
(33.9 \text { to } 71.3)\end{array}$ & $\begin{array}{l}112.2(59.2)^{\star} \\
(58.5 \text { to } 217.9)\end{array}$ & $\begin{array}{l}181.5(119.8)^{\star} \\
(69.5 \text { to } 382.9)\end{array}$ \\
\hline $\mathrm{LF} / \mathrm{HF}$ & $\begin{array}{l}0.31(0.07) \\
(0.16 \text { to } 0.40)\end{array}$ & $\begin{array}{l}0.49(0.26) \dagger \\
(0.29 \text { to } 1.18)\end{array}$ & $\begin{array}{l}0.75(0.32) \dagger \\
(0.31 \text { to } 1.34)\end{array}$ & $\begin{array}{l}0.25(0.07) \\
(0.16 \text { to } 0.38)\end{array}$ & $\begin{array}{l}0.37(0.17) \dagger \\
(0.27 \text { to } 0.84)\end{array}$ & $\begin{array}{l}0.59(0.30) \dagger \\
(0.27 \text { to } 1.30)\end{array}$ \\
\hline $\mathrm{HF}\left(\mathrm{ms}^{2} / \mathrm{Hz}\right)$ & $\begin{array}{l}19.6(9.9) \\
(9.4 \text { to } 27.3)\end{array}$ & $\begin{array}{l}38.2(24.0)^{\star} \\
(18.1 \text { to } 41.2)\end{array}$ & $\begin{array}{l}45.1(30.0)^{\star} \\
(18.0 \text { to } 93.0)\end{array}$ & $\begin{array}{l}24.6(10.4) \\
(10.3 \text { to } 38.9)\end{array}$ & $\begin{array}{l}52.6(33.7)^{\star} \\
(16.8 \text { to } 111.3)\end{array}$ & $\begin{array}{l}74.9(53.8)^{\star} \\
(21.3 \text { to } 142.1)\end{array}$ \\
\hline
\end{tabular}

All data are expressed as mean (SD) (range).

${ }^{\star} \mathrm{p}<0.01 v 1$ month, $\mathrm{\dagger p}<0.05 v 1$ month, $\neq \mathrm{p}<0.05 v 6$ months.

SDRR, mean of standard deviation of five minute successive normal RR intervals in two hours of data; TP, total spectral power components of heart rate variability in two hours of data; LF, low frequency components of heart rate variability in two hoursof data; $\mathrm{HF}$, high frequency components of heart rate variability in two hours of data.

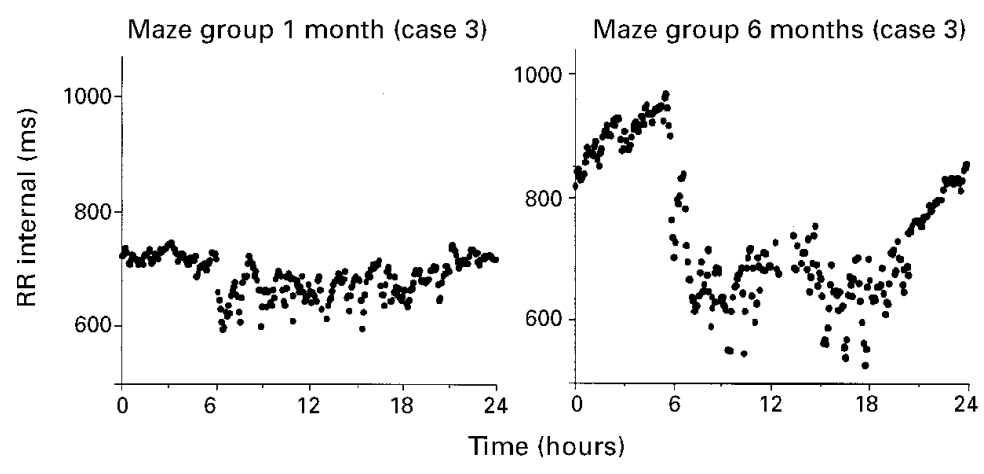

Figure 4 Serial changes in mean RR intervals of five minute segments over a 24 hour period, one and six months after the Maze procedure.
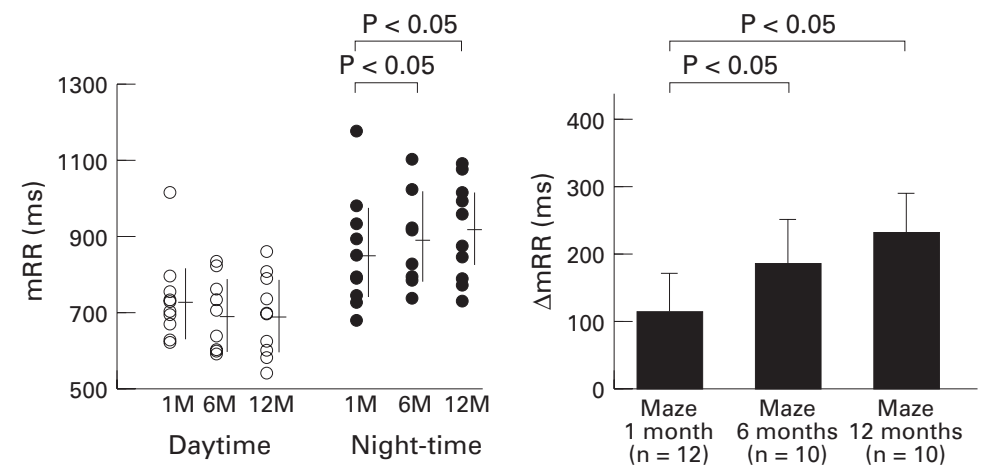

Figure 5 Left: Serial changes in the $m R R$ after the Maze procedure. Empty circles, daytime $m R R$; filled circles, night time $m R R$. Right: $\Delta m R R$ after the Maze procedure. $\Delta m R R$, difference in $m R R$ values between daytime and night time; $m R R$, mean $R R$ intervals in two hours of data.

in the Maze group (51.8 (19.4), range 33.9 to $71.3 \mathrm{~ms}^{2} / \mathrm{Hz}$ ) compared with the control group (249.9 (75.3), range 161.2 to $\left.351.1 \mathrm{~ms}^{2} / \mathrm{Hz}\right)$ ( $\mathrm{p}<0.01$, fig 3, right upper).

The daytime $\mathrm{LF} / \mathrm{HF}$ ratio was decreased in the Maze group (0.31 (0.07), range 0.16 to 0.40 ), compared with the control group (1.18 (0.46), range 0.75 to 2.03$)(\mathrm{p}<0.01$, fig 3 , left lower). Night time $\mathrm{LF} / \mathrm{HF}$ was also decreased in the Maze group (0.24 (0.07), range 0.16 to 0.38$) v$ the control group (0.81 (0.41), range 0.46 to 1.57$)(\mathrm{p}<0.01$, fig 3 , left lower).

Daytime HF components were decreased in the Maze group (19.6 (9.9), range 9.4 to $27.3 \mathrm{~ms}^{2} / \mathrm{Hz}$ ) compared with the control group (36.7 (7.1), range 26.6 to $47.7 \mathrm{~ms}^{2} / \mathrm{Hz}$ ) ( $\mathrm{p}<0.05$, fig 3 , right lower), and the night time
HF components were also decreased (24.6 (10.4), range 10.3 to $38.9 \mathrm{~ms}^{2} / \mathrm{Hz} v$ $79.1(32.1)$, range 33.9 to $118.0 \mathrm{~ms}^{2} / \mathrm{Hz}$ ) ( $\mathrm{p}<0.01$, fig 3 , right lower).

\section{SERIAL CHANGES IN HEART RATE VARIABILITY} AFTER THE MAZE PROCEDURE

Figure 4 shows mean RR intervals of five minute segments at six months after the Maze procedure in a representative case. The circadian variation of the mean $R R$ intervals was increased at six months compared with the one month data. Although there were no significant difference in the daytime mRR values (two hours of data), at six or 12 months after surgery the night time $\mathrm{mRR}$ values were increased compared with the one month data (845 (137) ms at one month, 885 (133) ms at six months, and 913 (130) ms at 12 months, fig 5 left). Thus the $\Delta \mathrm{mRR}$ (difference in $\mathrm{mRR}$ values between daytime and night time) was significantly increased six and 12 months after the Maze procedure (119 (60), range 14.9 to $139.6 \mathrm{~ms}$ at one month, 200 (64), 124.9 to $293.4 \mathrm{~ms}$ at six months, and 224 (62), range 132.2 to $296.0 \mathrm{~ms}$ at 12 months, fig 5 right).

In time domain analysis, both the daytime and night time SDRR values increased significantly at six and 12 months compared with the one month data $(p<0.01$, table 2$)$. The TP and $\mathrm{HF}$ components also increased at six and 12 months $(\mathrm{p}<0.01)$. Changes over time in the $\mathrm{LF} / \mathrm{HF}$ ratio were smaller than changes in the SDRR and in the HF component, but still significant $(\mathrm{p}<0.05)$.

\section{Discussion}

In this study, the Maze procedure suppressed the circadian variation of heart rate within one month after surgery, probably by damaging cardiac innervation to the sinus node. Indices of circadian variation improved over the following year, suggesting reinnervation of the sinus node.

INHIBITION OF CARDIAC INNERVATION OF THE SINUS NODE EARLY AFTER THE MAZE PROCEDURE The Maze procedure has been reported to stop atrial fibrillation and maintain sinus rhythm. ${ }^{1-4}$ However, it is often observed that the sinus node response to exercise is attenuated early after the procedure. ${ }^{6}$ In our study, the $\Delta \mathrm{mRR}$ (difference in mean RR interval values between 
daytime and night time) was significantly smaller in the Maze group than in the control group due to suppression of the night time $\mathrm{mRR}$ in the Maze group.

The heart is controlled by the combined influences of the sympathetic and parasympathetic divisions of the autonomic nervous system through their nerve endings on the main cardiac pacemaker, the sinus node. Heart rate is increased by sympathetic stimulation and decreased by parasympathetic stimulation. Changes in heart rate usually involve reciprocal actions of these two pathways. Analysis of heart rate variability provides information about cardiac sympathetic and parasympathetic nervous system function. ${ }^{9-11}$ The total power (TP) reflects the activity of the autonomic nervous system in the sinus node. The standard deviation of successive RR intervals (SDRR) mainly reflects vagal influences. ${ }^{10}$ Pagani et $a l^{11}$ have shown that the HF component reflects the specific influence of vagal activity on the heart rate and that the LF component is a sympathetic component modulated by parasympathetic activity. Thus the LF/HF ratio is usually used as an index of sympathetic activity.

Heart rate variability can be affected by many factors, such as age, previous myocardial infarction, diabetes mellitus, some types of drugs, and the heart operation itself. ${ }^{12}$ We attempted to control for the effects of most variables by observing strict inclusion criteria and by choosing as a control group patients who were having cardiac surgery without the Maze procedure.

In our study, indices of time and frequency domain analyses (SDRR, TP, LF/HF, and HF) were markedly suppressed in the Maze group but not in the control group, suggesting that cardiac innervation of the sinus node was inhibited by the Maze procedure itself, and not by cardiac surgery as such.

In general, complete suppression of parasympathetic influences causes a marked increase in heart rate whereas suppression of sympathetic influences causes only a slightly decrease in heart rate. Therefore parasympathetic tone usually predominates at rest, and a night time increase in parasympathetic tone results in a decrease in heart rate. In our study, the decreased circadian variation in $m R R$ values was mainly due to a decrease in the night time $m R R$, reflecting suppression of parasympathetic tone after the Maze procedure.

The anatomy of the autonomic nervous innervation of the human heart is not well described. In the canine heart, however, Randall and Ardell ${ }^{13}$ found that both parasympathetic postganglionic fibres and sympathetic fibres go around the superior vena cava to the sinus node. In our study, the Maze procedure was performed without separation of the superior vena cava in one patient (case 2), while separation was carried out in the other patients. However, the results did not differ, suggesting that damage to the innervation of the sinus node was probably done by the incisions made in the atrial wall.
SERIAL CHANGES IN HEART RATE VARIABILITY AFTER THE MAZE PROCEDURE

The indices of time and frequency domain analyses showed gradual improvement by six and 12 months after operation in the Maze group. The night time $\mathrm{mRR}$, the SDRR, and the HF component showed rapid recovery by six months, whereas the $\mathrm{LF} / \mathrm{HF}$ ratio, an index of sympathetic tone, showed late recovery. Thus reinnervation of parasympathetic fibres to the sinus node may be more rapid than reinnervation of sympathetic fibres after the Maze procedure.

Tamai et $a l^{6}$ reported that heart rate at peak exercise was attenuated at one month after the surgery combined with the Maze procedure, but recovered in the late phase after surgery. This was associated with improvement in exercise capacity. Improvements in all indices of heart rate variability in our present study support those results.

In animal models, reinnervation of parasympathetic nerves has been observed at 26 days after denervation of the heart, and reinnervation of sympathetic nerves at 74 days. ${ }^{14}$ However, other reports suggest that parasympathetic activity is not restored during the first postoperative month in man, but shows significant increases between three and six months, ${ }^{15}$ while sympathetic reinnervation occurs one year or later after orthotopic heart transplantation. ${ }^{16}$ We observed a similar pattern of changes in autonomic nervous tone in the present study, suggesting that reinnervation of the sinus node occurred six to 12 months after the Maze procedure.

\section{STUDY LIMITATIONS}

There are some limitations to this study. First, there were more patients with mitral valve disease in the Maze group than in the control group. Autonomic nervous function has been shown to be impaired in patients with mitral valve disease ${ }^{17}$ because of wall stress or fibrosis. However, all patients in the Maze group showed improvement over time, regardless of their underlying disease.

Second, atrial fibrillation may itself have influenced sinus node function. However, we found no correlation between indices of RR variability and the duration of atrial fibrillation. Therefore, we do not believe that atrial fibrillation influenced sinus node function in these patients.

Third, drug treatment was not discontinued during 24 hour Holter monitoring. However, there were no significant differences in indices of $R R$ variability between patients receiving digitalis or disopyramide and those not taking these drugs.

Fourth, we analysed two hours of data recorded during the daytime and night time, not 24 hours of data. However, we needed to do this so that we could assess the circadian variation in autonomic tone and avoid the influence of differences in daily activities among the patients.

Lastly, we did not use normalised units for the LF and HF portions of the total power 
because the absolute values of the time domain analysis variables were small.

\section{CONCLUSIONS}

Surgery combined with the Maze procedure in patients with atrial fibrillation markedly suppressed the circadian variation of heart rate over a 24 hour period within one month after surgery, mainly by damaging the innervation of the sinus node. However, at six and 12 months after the procedure, circadian variation in heart rate was restored, probably reflecting reinnervation of the sinus node.

1 Cox JL, Schuessler RB, Boineau JP. The surgical treatment of atrial fibrillation. I: Summary of the current concepts of the mechanisms of atrial flutter and atrial fibrillation. $\mathcal{F}$ Thorac Cardiovasc Surg 1991;101:402-5.

2 Cox JL, Canavan TE, Schuessler RB, Cain ME, Lindsay $\mathrm{BD}$, Stone C, et al. The surgical treatment of atrial fibrillation. II: Intraoperative electrophysiologic mapping and description of the electrophysiologic basis of atrial flutter and atrial fibrillation. $\mathcal{F}$ Thorac Cardiovasc Surg 1991;101: 406-26.

3 Cox JL, Schuessler RB, D'Agostino HJ, Stone CM, Chang BC, Cain ME, et al. The surgical treatment of atrial fibrillation, III: development of a definitive surgical procedure. $\mathcal{F}$ Thorac Cardiovasc Surg 1991;101:569-83.

4 Cox JL. The surgical treatment of atrial fibrillation. IV: Surgical technique. $f$ Thorac Cardiovasc Surg 1991;101:584gical

5 Kosakai Y, Kawaguchi AT, Isobe F, Sasako Y, Nakano K, Eishi K, et al. Cox-Maze procedure for chronic atrial fibrillation associated with mitral valve disease. $\mathcal{F}$ Thorac Cardiovasc Surg 1994;108:1049-55.

6 Tamai J, Kosakai Y, Yoshioka T, Ohnishi E, Takaki H, Okano Y, et al. Delayed improvement in exercise capacity with restoration of sinoatrial node response in patients after combined treatment with surgical repair for organic heart disease and the Maze procedure for atrial fibrillation. Circulation 1995;91:2392-9.

7 McLoughlin DE, Blitz A, Simmons J, Brodman R, Frame R, Bator S, et al. Electrophysiological effect of the Maze procedure on canine sinoatrial node function. PACE 1992; 15:2084-91.

8 Cox JL. Evolving application of the Maze procedure for atrial fibrillation. Ann Thorac Surg 1993;55:578-80.

9 Akselrod S, Gordon D, Ubel FA, Shannon DC, Barger AC, Cohen RJ. Power spectrum analysis of heart rate fluctuation. A quantitative probe beat-to-beat cardiovascular control. Science 1981;213:220-2.

10 Stein PK, Bosner MS, Kleiger RE, Conger BM. Heart rate variability: a measure of cardiac autonomic tone. Am Heart $\mathcal{F} 1994 ; 5: 1376-81$

11 Pagani M, Lombardi F, Guzzetti S, Rimoldi O, Furlan R, Pizzinelli $\mathrm{P}$, et al.. Power spectral analysis of heart rate variabilities as a marker of sympatho-vagal interaction in man and conscious dogs. Circ Res 1986;59:178-93.

12 Hogue CW, Stein PK, Apostolidou I, Lappas DG, Kleiger $\mathrm{RE}$. Alterations in temporal patterns of heart rate variability after coronary artery bypass graft surgery. Anesthesiology 1994;81:1356-64.

13 Randall WC, Ardell JL. Selective parasympathectomy of automatic and conductile tissues of the canine heart. Am $\mathcal{F}$ Physiol 1985;248:H61-8.

14 Peiss CN, Cooper T, Willman VL, Randall WC. Circulatory responses to electrical and reflex activation of the nervous system after cardiac denervation. Circ Res 1966;19:153-66.

15 Smith ML, Ellenbogen KA, Eckberg DL, Sheehan HM, Thames MD. Subnormal parasympathetic activity after cardiac transplantation. Am f Cardiol 1990;66:1243-6.

16 Wilson RF, Christensen BV, Olivari MT, Simon A, White CW, Laxson DD. Evidence for structural sympathetic reinnervation after orthotopic cardiac transplantation in humans. Circulation 1991;83:1210-20.

17 Stein KM, Borer JS, Hochreiter C, Okin PM, Herrold EM, Devereux RB, et al. Prognostic value and physiological correlates of heart rate variability in chronic severe mitral regurgitation. Circulation 1993;88:127-35. 